\title{
Social sources of cigarettes for youth: broadening the research base
}

\section{K M Ribisl}

\section{The social sourcing of cigarettes by youth is becoming an increasing problem}

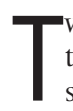
wo articles in Tobacco Control address the burgeoning problem of social sources of cigarettes for youth. Research over the past decade has shown that interventions to reduce youth access to tobacco products have not succeeded in reducing the availability of tobacco products to youth. In part, this is because most interventions have focused exclusively on reducing tobacco sales to minors at retail outlets. Although some of these interventions have been more successful than others in reducing the rate of sales to minors at stores, there are many other potential sources of cigarettes for youth. When there are "crackdowns" on sales to minors at stores, many youth simply switch their usual source of cigarettes. Social sources have simply filled the void. Epidemiologic studies have shown that US youth have increasingly relied upon noncommercial or social sources of cigarettes. ${ }^{1}$

Both of the recent studies ${ }^{23}$ help expand the knowledge base on social sources and extend the findings of epidemiologic studies. The study by Croghan $\mathrm{et}_{\mathrm{al}} \mathrm{l}^{2}$ is notable because it combines quantitative and qualitative methods to provide a richer understanding of the emerging issue of social sources. The findings about the underground "peer market" for cigarettes at schools are enlightening. Friends share cigarettes with other friends in a reciprocal fashion while student entrepreneurs appear to exploit other students by selling them cigarettes at high prices. Another interesting aspect of this study is the focus on the characteristics of the social source providers. Respondents who felt that they were part of a group that they identified as "troublemakers" and "rebels" were more likely to rely on commercial sources than those who interacted with friends who were "sporty" and "trendy". These findings will help illustrate some of the characteristics of youth who are social source providers, which will help in the development of interventions targeting these individuals. The study by Forster et $a l,{ }^{3}$ appearing in this issue of the journal, does an excellent job of making the case for broadening the scope of social availability to include more than just the source provider. They argue that the field should recognise all aspects of the social environment that "allow or promote tobacco use: sources of tobacco, places to use it, and reasons to use it". Another contribution of this study is the development of new scales to measure the social provision and acquisition of tobacco.

\section{MATRIX OF TOBACCO SOURCES}

In developing a more comprehensive view of youth access, we might think of a matrix of providers and modes of obtaining tobacco products. On one axis are the different providers, such as commercial sources (tobacco retailers, internet vendors, and vending machines) and noncommercial or social sources (parents, siblings and other family members, friends, acquaintances, and strangers). For each source, age appears to matter and peer sources appear to provide more often than adult social sources. On the other axis is the mode of obtaining tobacco products, such as purchasing, stealing, and "bumming" or borrowing. Much of the literature over the past decade has focused on reducing sales to minors at retail outlets, which is just one small square in the matrix. These two studies will help the tobacco control advocates better understand the other squares in the matrix. We may also need to take very different approaches depending on the particular mix of providers and modes of provision-for example, a campaign to prevent bystanders from buying cigarettes for minors outside of stores will look very different from a campaign focused on social exchanges among peers. Moreover, the amount of tobacco being provided from each source appears to vary. For instance, many regular smokers were purchasing whole packs at retail outlets versus receiving single cigarettes from peer-to-peer social sources.

One of the key issues that future research should explore is to identify which intervention strategies will work to reduce the social availability of cigarettes to youth. Forster $e t a l^{3}$ provide convincing evidence that youth who are the recipients of cigarettes are also those who share and provide them. Obviously, these cigarettes were obtained first from a commercial source, and then passed along to others. Consequently, Forster et al propose that interventions that effectively reduce commercial access will suppress social sources. ${ }^{3}$ It will be important for researchers to evaluate this strategy.

\section{. . given the reciprocal nature of social exchange of cigarettes, there are complex friendship ties involved}

There are few interventions that have sought to reduce social provision, and this will present challenges. First, given the reciprocal nature of social exchange of cigarettes, there are complex friendship ties involved. Getting a clerk or shopkeeper to stop selling to minors (many of whom they do not know) will probably be easier than getting friends not to share or sell cigarettes to each other. Second, there are far more intervention targets: any given community has far more social sources than commercial sources of cigarettes. ${ }^{4}$ Instead of just preventing stores from selling to minors, interventions would need to prevent a diverse group of family members, friends, and strangers from overtly or unwittingly providing cigarettes to minors. Moreover, evaluating interventions will be challenging, given the generally private and non-public nature of the exchange. When evaluating interventions to reduce tobacco sales at stores, compliance checks and surveys of youth smokers can assess whether sales to minors and perceived availability have been reduced. Conducting compliance checks of peerto-peer exchanges is virtually impossible, and self report surveys of youth will probably need to be the major method of evaluating interventions.

\section{TOBACCO INDUSTRY RESPONSE}

A final issue to consider issue is how the tobacco industry will react to the issue of increased social availability of cigarettes. In fact, the tobacco companies and retailer organisations appear to welcome this shift in sources because it deflects attention from tobacco companies marketing to youth or stores from profiting by selling cigarettes to youth. Philip Morris USA, for example, has developed a print campaign that cites data showing increased reliance on social sources and urges parents who smoke to secure their cigarettes so their children cannot steal them. Philip Morris USA also provides retailers with counter signs, "openclosed" signs, and window clings (plastic signage that hangs on glass walls) that 
say "HELP PREVENT UNDERAGE SMOKING-Don't buy cigarettes for kids". Thus, the problem of youth access is framed as a problem of careless parents and unconcerned bystanders buying cigarettes for minors. Finding ways to intervene and reduce social availability without playing into the hands of the industry is one other factor that will need to be considered.

Tobacco Control 2003;12:115-116
Correspondence to: Kurt M Ribisl, PhD, Department of Health Behavior and Health Education, UNC School of Public Health, Chapel Hill, NC 27599-7440, USA; kurt_ribis|@unc.edu

\section{REFERENCES}

1 Jones SE, Sharp DJ, Husten CG, et al. Cigarette acquisition and proof of age among US high school students who smoke. Tobacco Control 2002;1 1:20-5.

2 Croghan E, Aveyard P, Griffin C, et al. The importance of social sources of cigarettes to school students. Tobacco Control 2003;12:67-73.

3 Forster J, Chen V, Blaine T, et al. Social exchange of cigarettes by youth. Tobacco Control 2003;12:148-54.

4 Ribisl KM, Norman GJ, Howard-Pitney B, et al. Which adults do underaged youth ask for cigarettes? Am J Public Health 1999;89:1561-4. 